\title{
A new species of Amphisbaena (Squamata, Amphisbaenidae) from state of Maranhão, Brazil
}

\author{
Miguel Trefaut Rodrigues ${ }^{1}$, Gilda V. Andrade ${ }^{2}$ and Jucivaldo Dias Lima² \\ 1 Universidade de São Paulo, Instituto de Biociências, Departamento de Zoologia, Caixa Postal 11.461, 05422-970, São \\ Paulo, SP, Brazil. E-mail: mturodri@usp.br. \\ ${ }^{2}$ Universidade Federal do Maranhão, Departamento de Biologia, Av. dos Portugueses, s/n, Campus do Bacanga, \\ 65080-040, São Luís, MA, Brazil.
}

\begin{abstract}
A new species of Amphisbaena (Squamata, Amphisbaenidae) from state of Maranhão, northeastern Brazil. Amphisbaena ibijara sp. nov. is described from Urbano Santos (Fazenda Santo Amaro), state of Maranhão, Brazil. The new species is a small amphisbaenian with four precloacal pores, nasals in broad contact at midline, no major fusions of head scales, 239-250 body annuli, 23-25 caudal annuli and 1416 dorsal and 14-16 ventral segments per annuli at midbody. Other attributes of the new species are: suture between frontals slightly smaller than parietal suture and much longer than nasal suture, three supralabials (the first being the smallest), second infralabial the largest and much larger than postmental, two rows of postgenials, and absence of a postmalar row.
\end{abstract}

Keywords: Squamata, Amphisbaenidae, Amphisbaena ibijara, cerrado, Brazil.

\section{Introduction}

In the last years new species of amphisbaenians have been described for South America, most discovered during surveys carried out in previously unexplored regions. Several years ago, one of us (GVA) was invited by the Comercial e Agrícola Paineiras Ltda, a firm from state of Maranhão to undertake a herpetological survey at Fazenda Santo Amaro, municipality of Urbano Santos, an area with approximately 100 ha kept unaltered by the owners since its acquisition, 21 years ago. Although most of the

Received 27 March 2003

Accepted 19 July 2003

Distributed 31 October 2003 habitats from the area were disturbed we obtained during this survey a species of Amphisbaena so distinct from all other congeners that it is described below as a new species.

\section{Species Description}

Amphisbaena ibijara sp. nov.

(Figures 1 and 2)

Holotype - MZUSP 91989, Fazenda Santo Amaro (0313'34"-0314'58'S, 4324'59"$43^{\circ} 25^{\prime} 45^{\prime \prime} \mathrm{W} ; 41 \mathrm{~m}$ altitude): Urbano Santos: state of Maranhão, Brazil, collected by J. R. F. Lima, G. B. Santos, and G. V. Andrade on 29 June 2001; field number G.Andrade 049. 

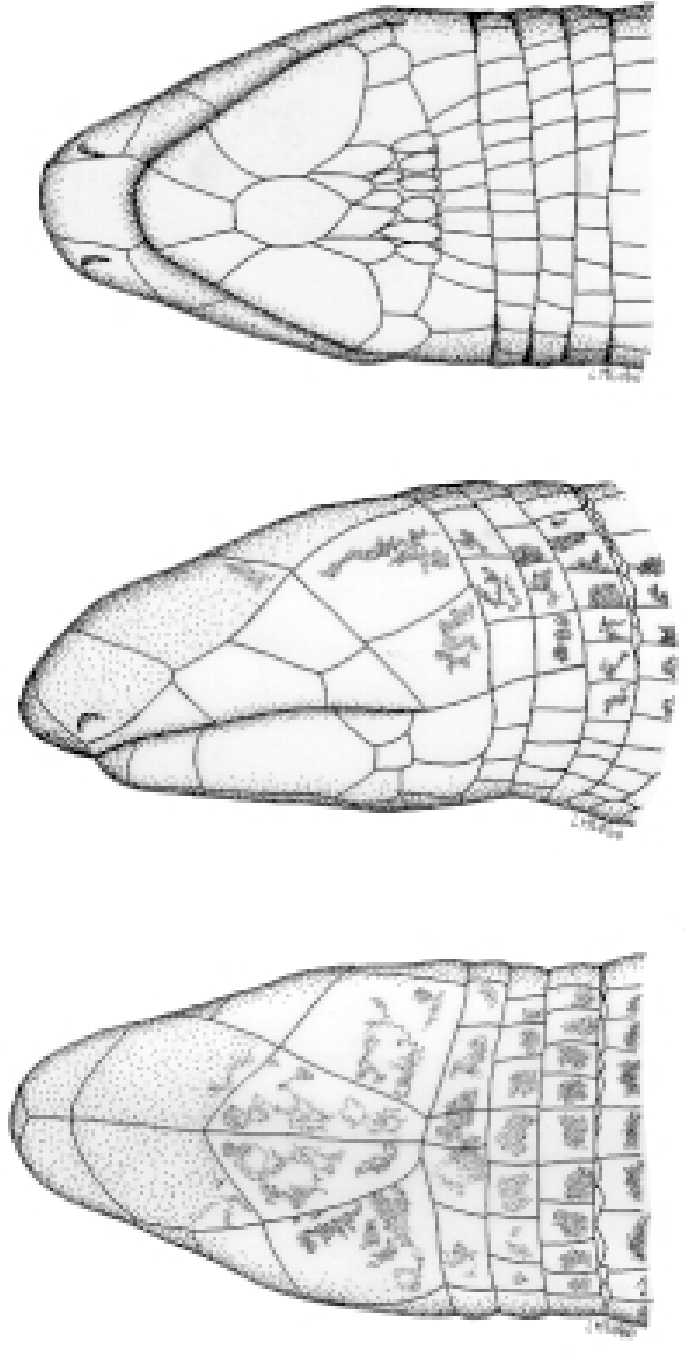

Figure 1 - Amphisbaena ibijara: ventral, lateral, and dorsal views of head (MZUSP 91989, holotype). Bar = $1 \mathrm{~mm}$.

Paratypes - MZUSP 91984-91988, 9199091992, same data as for the holotype, collected by G. V. Andrade, J. D. Lima, J. R. Lima, G. B. Santos, L. Dominici, and J. O. Gomes between October 2000 and June 2002.
Etymology - ibijara derives from Tupi vocabulary. It was one of the words in use for amphisbaenians at the time of early colonization of Brazil. It means the "lord of the ground" or ground inhabitant.

Diagnosis - A small Amphisbaena with four precloacal pores, nasals in broad contact at midline and without fusions of head scales: rostral, nasals, frontals, parietals and labials are discrete. Three supralabials, first one smallest; two infralabials, second the largest and larger than postmental. Two rows of postgenials, postmalar row absent. Suture between frontals slightly smaller than parietal suture and much larger than nasal suture. Body annuli 239-250, caudal annuli 23-25, 14-16 and 14-16 dorsal and ventral segments per annuli at midbody, respectively.

Description of the holotype - (Figure 1). A small amphisbaenid with head not distinct from neck, a slightly prominent and acuminate snout, mouth ventral, a total length of $235 \mathrm{~mm}$ $(222+13)$, and $6 \mathrm{~mm}$ diameter at midbody. Rostral longer than wide, clearly visible and subtriangular from above, ventrally expanded, wider and concave posteriorly, contacting first supralabial and nasal; contact with supralabial about as long as the diameter of nostril. Nasals, frontals and parietals in contact at midline. Nasals quadrangular, in broad contact with rostral, first supralabial and frontal, and contacting second supralabial; their suture at midline longer than part of rostral visible from above. Nostrils lateral, in the anteroventral part of nasal. Frontals larger than nasals, longer than wide, their size at midline suture identical to size at labial margin. Suture between frontals slightly smaller than parietal suture. Parietals subtriangular, longer than wide, in broad contact with a large temporal and slight contact with ocular. Occipitals absent. Three supralabials, first and third smaller and similar in size, second diagonally oriented, largest and highest, contacting nasal and frontal dorsally, in largest 


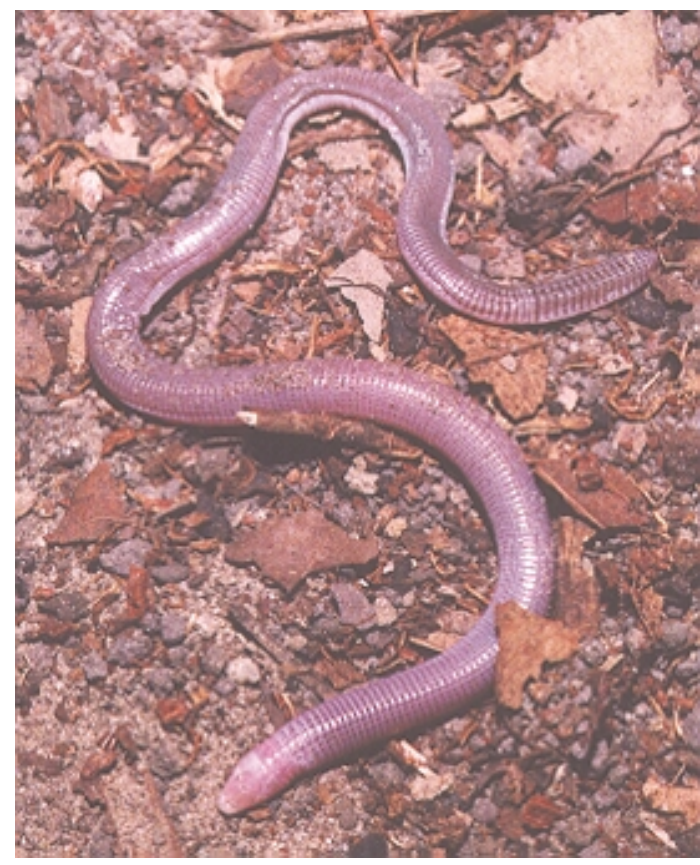

contact with the latter. Ocular quadrangular, contacting second and third supralabials, frontal, and first temporal; eye indistinct. First temporal as wide as frontal and much larger than ocular, contacting ventrally a smaller temporal scale. Posterior margin of head formed by parietals and temporals, almost straight, in contact with first annulus.

Mental smaller than rostral, as long as wide, wider anteriorly; lateral margins straight, converging posteriorly to a large and truncate posterior margin. A large ellipsoid postmental, longer than wide, as long as mental, posteriorly contacting four smaller elongate postgenials. Three infralabials, third the smallest, second the largest and the largest scale on the ventral aspect of the head, with about the same size as the frontal. Second infralabial in broad contact with postmental and malar, the later followed by the ventral scales of the first annulus posterior to angulus oris; postmalar row absent. Paired malars and enlarged scales following them separated at midline respectively by six and

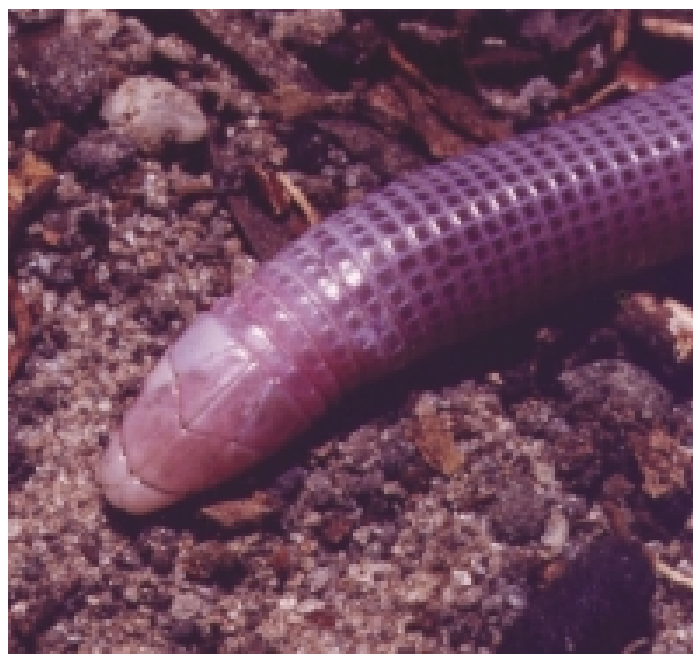

Figure 2 - Amphisbaena ibijara: color in life of the paratype (MZUSP 91986) from Fazenda Santo Amaro, Urbano Santos, state of Maranhão, Brazil.

seven elongate scutes, larger than those following postmental.

Body annuli well marked, with regular and conspicuous segments separated by lateral grooves. First three annuli showing some asymmetric fusion of dorsal segments, from there on the segments become regularly quadrangular and progressively longer than wide; 240 body and 10 caudal annuli; 14 dorsal and 14 ventral segments per annuli at midbody. Ventral segments larger towards the midventral area, the two midventral segments of each annulus distinctively enlarged between the fourth body segment and preanal region.

Four precloacal pores. Anal flap semicircular, with eight enlarged scutes, increasing in size towards midline. Tail segments longer than those of body. Tail regenerated at the eighth annulus; tip of tail smooth, rounded.

Dorsal ground color dark brown with center of segments darker. Only two or three series of ventral segments pigmented centrally, rest of the belly creamy white, immaculate. Head creamy 
Table 1 - Body lenght (BL), tail lenght (TL), head width (HW), head lenght (HL), number of body and caudal annuli, number of dorsal/ventral segments per annuli at midbody, and number of precloacal pores for the type series of Amphisbaena ibijara sp. nov. from Urbano Santos (Fazenda Santo Amaro), state of Maranhão, Brazil. (*) holotype.

\begin{tabular}{ccccccccc}
\hline MZUSP & BL $(\mathrm{mm})$ & TL $(\mathrm{mm})$ & HW $(\mathrm{mm})$ & HL & Body annuli & Caudal annuli & Segments & Pores \\
\hline $91989^{*}$ & 222 & 13 & & & 240 & 10 & $14 / 14$ & 4 \\
91984 & 208 & 25 & 4.6 & 7.1 & 248 & 25 & $15 / 15$ & 4 \\
91985 & 195 & 24 & 4.5 & 6.9 & 240 & 23 & $15 / 14$ & 4 \\
91986 & 150 & 17 & 3.9 & 5.5 & 248 & 24 & $16 / 15$ & 4 \\
91987 & 88 & 10 & 3.0 & 4.8 & 239 & 24 & $16 / 16$ & 4 \\
91990 & 238 & 11 & 4.9 & 7.1 & 244 & - & $16 / 14$ & 4 \\
91991 & 213 & 26 & 4.8 & 7.1 & 248 & 24 & $16 / 14$ & 4 \\
91992 & 215 & 8 & 4.6 & 7.3 & 250 & - & $15 / 14$ & 4 \\
\hline
\end{tabular}

white smudged with brown. Tail color following the pattern described for body. Tip of tail immaculate.

Variation - Table 1 shows the most relevant variation in the type series which did not affect the size or the relative position of the cephalic scutes. Precloacal pores are almost indistinct in MZUSP 91984, 91986, 91990, and 91992.

Natural History - All specimens were obtained during a herpetofaunal survey carried out at Fazenda Santo Amaro, a property of Comercial Agrícola Paineiras Ltda, municipality of Urbano Santos. The area is situated in the northeastern part of state of Maranhão, near the contact between the septentrional limit of the cerrado with the transitional open areas to the caatinga (Ab'Saber 1970, IBGE 1977). The climate is tropical megathermic. Annual precipitation in the area is approximately $1800 \mathrm{~mm}$ and concentrated in the rainy season: $89 \%$ of rain falls from December to May; the period extending from July to October is very dry with almost no rainfall. Annual mean temperatures vary between 26 and $27^{\circ} \mathrm{C}$. Although the cerrado with gallery forests was formerly the prevalent physiognomy in the region, the area is now heavily disturbed by human activities. The sampled area encompasses about 100 ha and includes a fragment of gallery forest along Mocambo river, a fragment of a semideciduous mesophyllous secondary forest, Eucalyptus plantations, and open disturbed areas for cattle ranching. Sandy soils and redyellowish latosols occur in the area with predominance of the former.

The area was sampled with two different blocks of pitfall traps. In the first, 150 "Y" shaped sets of pitfalls (four 10-L buckets separated by approximately $4 \mathrm{~m}$ ) without drift fences were placed in the following associations of habitat/landscape: Eucalyptus plantations (45 sets), gullies (33), and gallery forest, mesophyllous forest, open areas, and clearings (18 sets each). A second sampling scheme consisting of a line of four 37-L buckets separated by $15 \mathrm{~m}$ was used. In this scheme all buckets were interconnected by a drift fence which extended $2 \mathrm{~m}$ beyond the external buckets. The following habitats were sampled with this last method: gallery forest (3 sets), Eucalyptus groves (3 sets), and mesic forest (9 sets). A total of 14 specimens of Amphisbaena ibijara were collected in the traps. Eleven were caught in the first block in the following habitats: Eucalyptus plantation (7), gullies (2), and gallery forest (2). In this first trapping grid, 
which remained open from June to May 2002, two young specimens of $A$. alba (ca. $250 \mathrm{~mm}$ SVL) and a juvenile Leposternon polystegum $(\mathrm{SVL}=212 \mathrm{~mm})$ were also collected. Of the three specimens obtained in the second block, one was found per category of habitat sampled. This last grid was opened for 10 consecutive days per month from May to June 2002, a total effort equivalent to 1200 buckets/day. Five additional specimens of Amphisbaena ibijara were incidentally found while setting the pitfall traps, two in Eucalyptus plantations and three in mesophyllous forests.

Considering the extent and period of sampling, the fact that we caught only part of the specimens crossing the sampled area, and that large specimens can escape from the smaller pitfalls, Amphisbaena ibijara could be considered relatively common. Eleven specimens were collected in the dry season, eight during the rainy season. Two young specimens (SVL 88 and $94 \mathrm{~mm}$ ) collected in September suggest that reproduction occurs during the dry season. Of the total number of specimens collected, eleven are still been kept alive at São Luis.

\section{Discussion}

The systematics of Amphisbaena is still in its infancy. New species are regularly described, but we still lack a phylogenetic hypothesis to discuss their relationships. Identifications, diagnosis, and comparisons among the more than 50 South American species (Vanzolini 2002) rely on similarity and are specially based on counts of body annuli, body segments, and number of pores. A comprehensive compilation of the identification cues for all South American species of Amphisbaena, assembling data from literature and from direct specimen examination was presented recently as a matrix-format-key (Vanzolini 2002). Compared with the referred key and the associate geographical distribution, A. ibijara can be immediately separated from most congeners. Among species with four precloacal pores, only four, A. cunhai, A. medemi, A. carvalhoi, and A. frontalis, have numbers of body annuli (239-250), tail annuli (23-25), and dorsal/ventral segments per annuli at midbody (14-16/14-16) similar to A. ibijara: All these species, like A. ibijara, are small sized, without major fusions on head scutes, and with relatively long tails. Additionally, the number of caudal annuli of these species is close to or higher than 20.

Amphisbaena cunhai Hoogmoed and ÁvilaPires, 1991, from the Amazonian part of the state of Rondônia, has 226-239 body and 25-26 tail annuli, and 14-16/14-18 segments at midbody, but differs from A. ibijara (characters in parenthesis from here on) in important characters. In A. cunhai the first supralabial is the largest (the smallest); compared with frontal and parietal sutures, the midline suture between nasals is the longest (the shortest); there is no autotomy constriction (present), and a conspicuous dorsal sulcus is present (absent). Amphisbaena carvalhoi Gans, 1965, from Poção, municipality of Pesqueira, state of Pernambuco, is also similar to A. ibijara in meristic characters, 231-245 body and 19-22 tail annuli, and 12-14/14-16 segments at midbody, but they are very distinctive. In A. carvalhoi the frontal suture is much longer than parietal suture (shorter), and the second infralabial is smaller than the postsymphysial (much larger). In $A$. medemi Gans and Mather, 1977, from Departamento Bolivar, Colombia, differences in pholidosis are even more striking: there is no overlap in body (230-235) and tail annuli (1718 ), and only slight overlap in midbody segments (14-16/16-18). Additional differences between these species include: nasals totally separate or in slight contact at midline in $A$. medemi (in broad contact), supralabials equal in size (first much smaller), parietal suture shorter than frontal suture (longer). Finally, A. frontalis Vanzolini, 1991, from the dune fields of the Rio São Francisco, state of Bahia, has 257-272 body and 23-24 tail annuli, and 14-16/14-16 midbody segments. Nevertheless, A. frontalis differs from 
A. ibijara by presenting a pair of parietals with lateral margins varying from straight to slightly concave and with a posterior border wide and truncate (straight and diagonally oriented, and narrow respectively).

\section{Acknowledgements}

We thank Fundação de Amparo à Pesquisa do Estado de São Paulo (FAPESP), Conselho Nacional de Desenvolvimento Científico e Tecnológico (CNPq) PELD/ECOCEM/ TROPEN and Comercial e Agrícola Paineiras Ltda for support. For their invaluable help in the field, we thank Janaina R. F. Lima, Gissele B. Santos, Leonardo D. Cruz and Jerriani O. Gomes. We also thank Luciana Lobo for the drawing, and Hussam Zaher and Carolina Castro-Mello for access to specimens at MZUSP.

\section{References}

Ab'Saber, A. N. 1970. Províncias geológicas e domínios morfoclimáticos no Brasil. Geomorfologia 20: 1-25.

Gans, C. 1965. On Amphisbaena heathi Schmidt and A. carvalhoi, new species, small forms from the northeast of Brazil (Amphisbaenia: Reptilia). Proceedings of the California Academy of Sciences (Fourth series) 31: 613-630.

Gans, C. and S. Mathers. 1977. Amphisbaena medemi, an interesting new species from Colombia (Amphisbaena, Reptilia), with a key to the amphisbaenians of the Americas. Fieldiana Zoology 72: 21-46.

Hoogmoed, M. S. and T. C. S. Ávila-Pires. 1991. A new species of small Amphisbaena (Reptilia: Amphisbaena: Amphisbaenidae) from western Amazonian Brazil. Boletim do Museu Paraense Emílio Goeldi, série Zoologia 7: 77-94.

IBGE. 1977. Geografia do Brasil. Vol. 1. Região Norte. Rio de Janeiro. Instituto Brasileiro de Geografia e Estatística. $466 \mathrm{pp}$.

Vanzolini, P. E. 1991. Two further new species of Amphisbaena from the semi-arid northeast of Brazil (Reptilia, Amphisbaenia). Papéis Avulsos de Zoologia, São Paulo 37: 347-361.

Vanzolini, P. E. 2002. An aid to the identification of the South American species of Amphisbaena (Squamata, Amphisbaenidae). Papéis Avulsos de Zoologia, São Paulo 42: 351-362. 